This item is the archived peer-reviewed author-version of:

The enriching limitations of the physical world

\title{
Reference:
}

Van Campenhout Lukas, Frens Joep, Hummels Caroline, Standaert Achiel, Peremans Herbert.- The enriching limitations of the physical w orld Personal and ubiquitous computing - ISSN 1617-4909 - (2018), p. 1-18

Full text (Publisher's DOI): https://doi.org/10.1007/S00779-018-1176-8

To cite this reference: https://hdl.handle.net/10067/1528880151162165141 


\section{The Enriching Limitations of the Physical World}

First author: Lukas Van Campenhout. University of Antwerp, Faculty of Design Sciences, Product Development. Prinsstraat 13, 2000 Antwerp, Belgium. Lukas.vancampenhout@uantwerpen.be / Mobile: + 32 (0) 496528206 / ORCID 0000-0001-6680-4464

Second author: Joep Frens. Eindhoven University of Technology, Industrial Design. PO Box 513, 5600 MB Eindhoven, The Netherlands

Third author: Caroline Hummels. Eindhoven University of Technology, Industrial Design. PO Box 513, 5600 MB Eindhoven, The Netherlands

Fourth author: Achiel Standaert. University of Antwerp, Faculty of Design Sciences, Product Development. Prinsstraat 13, 2000 Antwerp, Belgium

Fifth author: Herbert Peremans. University of Antwerp, Faculty of Applied Economics. Prinsstraat 13, 2000 Antwerp, Belgium

\section{Funding}

This research did not receive any specific grant from funding agencies in the public, commercial, or not-for-profit sectors.

\section{Abstract}

In this paper, we investigate the third stand, our perspective on embodied interaction with digital products and systems. First, we discuss its background of dematerialization, an ongoing evolution in which physical products and information carriers disappear, and become immaterial information packages and on-screen applications. We establish how dematerialization influences both design research and design practice. Next, we present a digital payment terminal that we designed in order to explore the added value of our third stand perspective. In an experiment, we compare it with an existing payment terminal. The results of the experiment reveal that the third stand terminal scores higher on hedonic values, like beauty and stimulation. The existing terminal scores higher on pragmatic values, like ease-of-use and efficiency. We position the third stand as a design approach that pleas for embodiment from a hedonic perspective, and propose to extend the argument for embodiment beyond pragmatic values. Finally, we suggest that the third stand celebrates the limitations of the physical world instead of trying to overcome them, and gives rise to specific emotional values like attentiveness, profundity and preciousness.

Keywords - Dematerialization, Industrial Design, Embodied Interaction, User Experience. 


\section{Introduction}

As computational technology becomes ubiquitous and everyday products increasingly contain digital components, we witness a striking evolution: some products are completely absorbed by the digital world, and tend to disappear or dematerialize [1, 41]. Dematerialization occurs when a physical object disappears or becomes an on-screen manifestation, i.e. an icon or text on a display. This is the case with information carriers: music CDs [40], cash money [45], books, newspapers [48], maps and photographs [47]. On the other hand, function-specific digital products like pocket calculators, GPS devices, digital agendas, cameras, cell phones and alarm clocks disappear as well and become on-screen applications on smart phones and tablets [55]. We stated that dematerialization occurs when a physical object moves from the physical to the digital world. The object dissolves and its content is detached [13,14] and added to the digital world (Fig. 1). The latter extends, at the expense of the physical world.

Why do products dematerialize? Because, once digital, they are freed from their physical limitations and obtain an apparently limitless flexibility and availability. Thanks to dematerialization, our entire music album collection fits in our pocket, and we have access to our finances, wherever we go. On the other hand, we believe dematerialization is not without pitfalls. Our interaction with digital devices is limited to button pushing, or finger gestures on a multi-touch display, and is in that sense less rich than the action routines that were common in, for example, the vinyl era [4]. Moreover, our interaction with digital devices is a standardized one, which has homogenized a whole range of different human tasks and activities [38].

We formulated a manifesto [54], in which we stated that dematerialization should not proliferate freely, but should be well considered before it is applied. We stated that, in order to enjoy its benefits and avoid its pitfalls, dematerialization should be guided by product design. Our research centres on the question of how product design can do this. Starting from rich interaction [18], we established a design perspective, the third stand [55], that is intended to provide such guidance, and positioned it in the wider research area of embodied interaction [10]. In this paper, we further investigate the third stand.

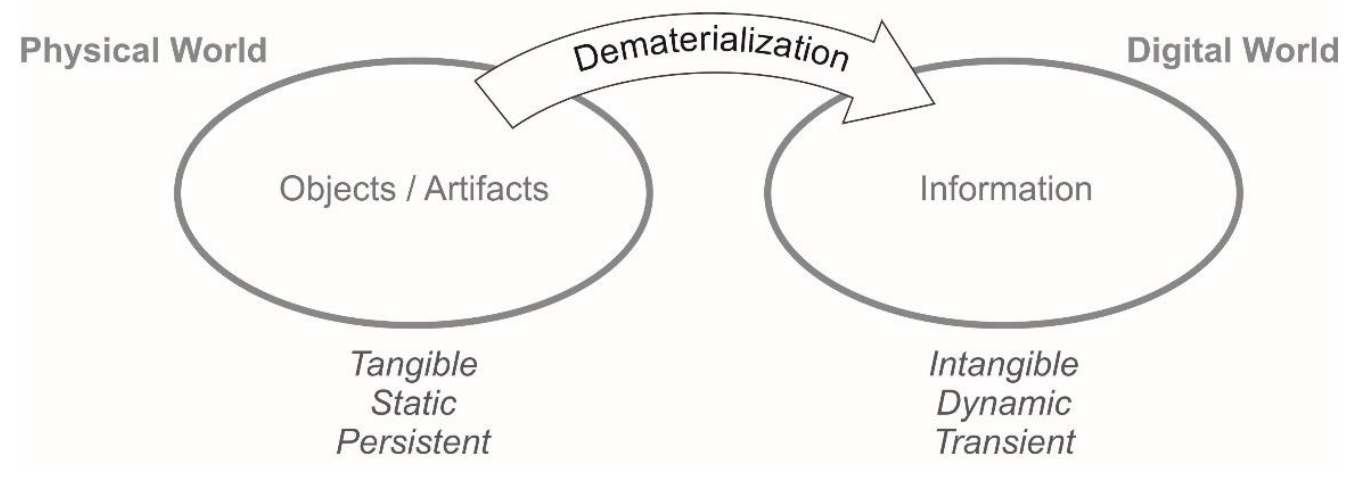

Fig. 1 Physical objects dematerialize when they move from the physical to the digital world 
We employ Research through Design (RtD) to investigate the third stand [39], and more specifically, a philosophical approach to it $[59,60]$. This means that the researcher, starting from his personal observations and reflections, seeks to "transform the world from its current state to a preferred state" [60]. The third stand is our preferred state, and, in previous papers [54, 55], we defined its foundations through several design iterations. In this paper, we take this definition a step further. We want to understand how the third stand is different from other embodied interaction frameworks. We explicitly formulate a research question:

- What is the added value of the third stand?

We introduce a research prototype [20,60,61], a digital payment terminal, which represents the third stand. In order to determine where the added value of the third stand lies, we test the payment terminal in a laboratory setting [39]. From the results of this experiment, we seek to deepen our understanding of the third stand.

This paper contains 7 main sections, from which this introduction is the first. In Section 2, we distinguish two approaches to dematerialization: the first stand and the second stand. In Section 3, we present and position the third stand by demonstrating a research prototype: the Experimental Payment Terminal (EPT). In Section 4 and 5, we present a lab experiment in which we compare the EPT with an existing payment terminal. In Section 6, we discuss the results of this experiment, and relate them to our research question. Finally, in Section 7, we reflect on the delivered work, and suggest how the third stand can contribute to the embodied interaction research agenda.

\section{Different perspectives on dematerialization}

In this section, we distinguish two approaches to dematerialization, which we call respectively the first and the second stand. These approaches are not intended to provide a basis for a decisive taxonomy of digital systems. We coin the first and second stand, since they form the conceptual background against which we place our own framework, the third stand.

\subsection{The first stand}

\subsubsection{Description}

We employ the first stand towards dematerialization to denote a particular research perspective: the initial framework of tangible interaction [35], as it was formulated in the nineties. This early, radical form of tangible interaction wants to make our interaction with digital phenomena more natural and intuitive, by literally embodying these data within physical objects or tangibles [12, 50]. As such, the digital data become graspable and manipulable [17, 28]. An archetypical example of tangible interaction is the MediaBlocks system [49]. Small wooden blocks embody digital images, a text file, or a software application. When you have different blocks, embodying different files, you can order these files by physically dividing into groups or piling up the wooden blocks that embody them. When you want to share a file with someone else, you don't attach this file to an e-mail, but literally hand its embodying block over to this person.

The benefit of the first stand is related to the argument of familiarity [9, 10]. We, humans, are familiar with the physical world that surrounds us, with its animals, plants and objects, and with the 
other people that inhabit it. We are familiar with it in the sense that we have highly developed skills for interaction in and with this world, its rich affordances [21], action-potentials [8] and specific action routines. The idea now is to exploit this familiarity in our interaction with digital products and systems, in order to lend it the same naturalness [11] and intuitiveness [30, 31] that characterize our interaction with the physical world.

We want to emphasize that the first stand was not defined as a reaction to dematerialization, but rather as a different way to interact with digital data. However, it does advocate a movement towards more physicality, and in that sense counterbalances the movement of dematerialization (Fig. 2).

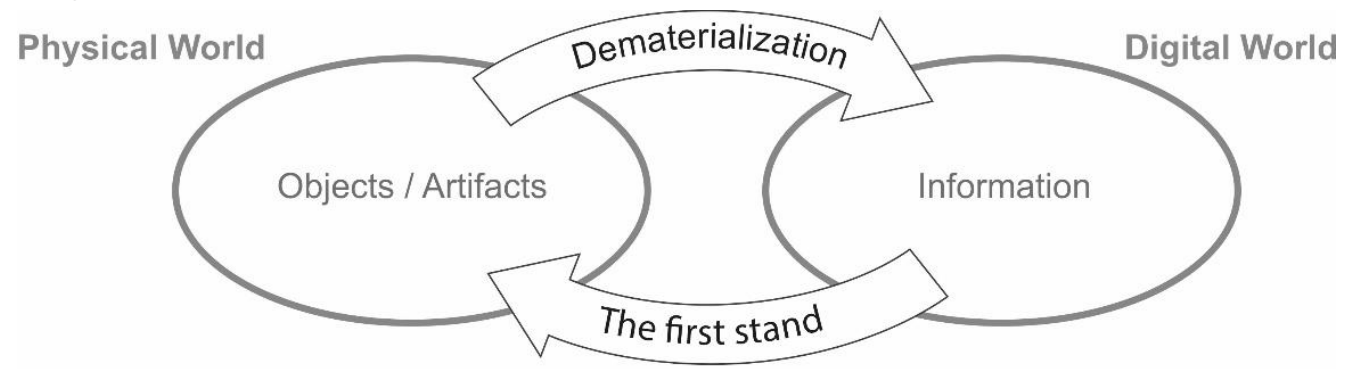

Fig. 2 The first stand as an opposite process of dematerialization

\subsubsection{Criticism}

Because the first stand highly values the familiarity of the physical world, it tends to make digital information as physical as possible [36], in order to maximize the intuitiveness and naturalness of our interaction with it. Holmquist et al. [28] ideated a music system, where music albums would be embodied by physical tokens, offering the user the familiarity of the physical world, in a digital system. This idea, although visionary in our opinion, never became a reality. Dematerialized music albums, under the form of MP3 files, turned out to have a higher flexibility and availability than any physical object, and consequently, they conquered the world. Our criticism of the first stand concerns its emphasis on the physical, which possibly leads to an underappreciation of the digital's flexibility and availability [54].

\subsection{The second stand}

\subsubsection{Description}

The stand that is taken towards dematerialization by the current generation of digital products, emphasizes the digital world. We call it the second stand. The second stand embraces dematerialization and sees it as a way of making things more efficient and effective, mainly because of the digital world's flexibility and availability. Information carriers like music records, CDs, cash money and books disappear and release their content, which becomes available without the physical burden that the carriers brought about. Typical second stand products are MP3 players, payment terminals, e-books and digital cameras. In a previous publication [55], we argued that also today's smart phones and tablet computers are exponents of dematerialization and the second stand. Both devices typically involve a multi-touch display, which dematerialized the physical control element 
and replaced it with a flexible amount of virtual push buttons, dials and levers behind a glass plate. This led to another wave of dematerialization, in which function-specific digital products like pocket calculators and cameras became applications on smart phones and tablets.

\subsubsection{Criticism}

Our criticism on the second stand concerns the aforementioned pitfalls that accompany it. We regret the loss of physical richness that accompanies dematerialization, and its tendency to transform rich specific and expressive action routines into generic and standardized ones on a keypad and a display. Second stand products employ an interface that feels "stuck on", and does not necessarily fit the overall meaning of the product [8]. Since displays typically employ representations of the physical world (for example, the desktop metaphor), they demand interpretation, and result in an interaction style that relies on abstraction and largely aims at the cognitive [38]. As a consequence, second stand products feel "computeresque" [8].

\section{The third stand and the Experimental Payment Terminal}

In this section, we present our own perspective on dematerialization, by demonstrating a research prototype. This prototype is a digital payment terminal, and was designed by the first author. We call it the Experimental Payment Terminal, or EPT (Fig. 3). We first sketch its background in dematerialization. Next we present the EPT and its interaction routine, and third, we discuss how the EPT embodies the third stand.

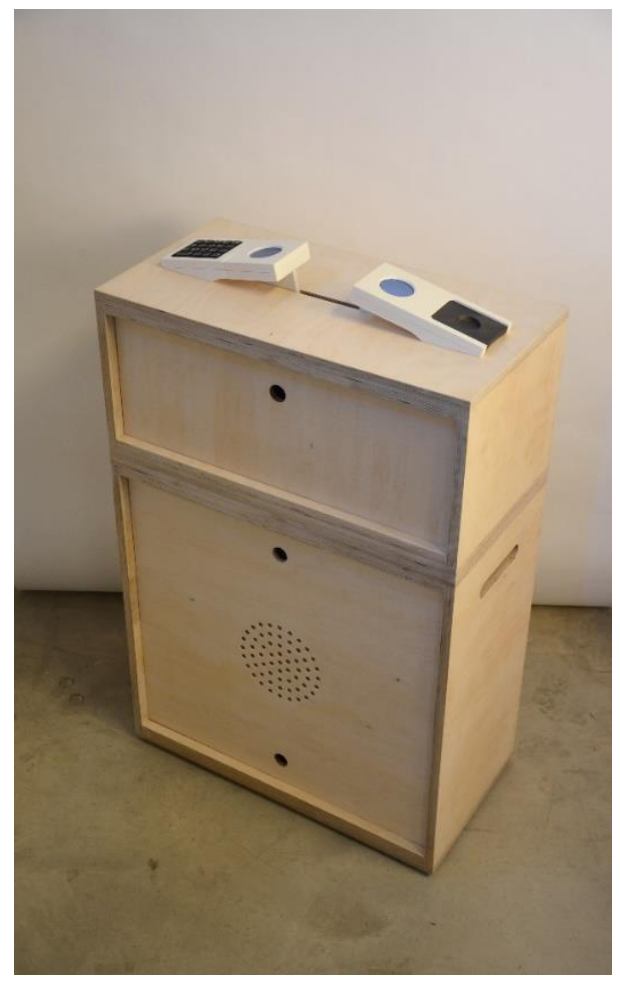

Fig. 3 The Experimental Payment Terminal or EPT 


\subsection{Background: dematerialization of cash money}

Paying with cash money, coins and bills, is increasingly replaced by paying with credit cards or smart phones. As such, cash money is dematerializing. Technological manifestations like NFC technology and mobile payment speed up the move to a cashless society. A stream of second stand products floods the market: digital payment terminals with a keypad/display setup and/or a multitouch display. These payment terminals come with payment interaction routines that are little expressive: the acts of inserting a smart card in a slot, entering a PIN code on a keypad or holding a smart phone near a sensor have little meaning for us, in the sense that they don't express the functionality that is opened. They could be equally applied in the task of opening a secured door, or logging into a computer network. Worldline's XENTA, described in 4.2, is such a terminal.

However, a payment routine between two persons possesses specific characteristics: one person hands over an amount of money to another person. The question we asked ourselves was: can we design a digital payment terminal that offers the flexibility and availability of the digital, while preserving the expressiveness of payment with cash money [53]?

\subsection{Description of the EPT's interaction routine}

The EPT comes with a token (Fig. 4), which is the property of the customer, and which can be used to execute a payment interaction on the terminal. The payment terminal is integrated in a rectangular wooden case, which acts as shop counter. It consists of three modules: the vendor module, the customer module, and the traveller (Fig. 4). We now describe the EPT's interaction routine. A video of this routine can be found on https://www.youtube.com/watch?v=enpEUMXMyN8

When not active, the traveller rests against the vendor module, and both modules form one visual unit with a similar shape as the customer module. Both entities, the vendor module and the traveller versus the customer module, are positioned opposite to each other. The whole setting is visually symmetrical and well balanced (Fig. 4).

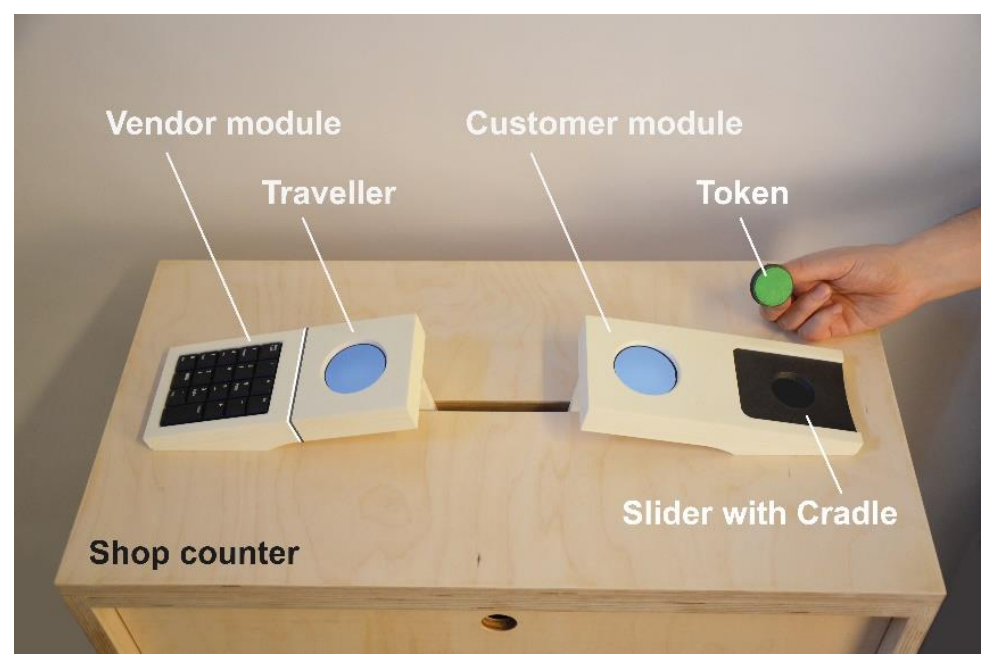

Fig. 4 The different parts of the EPT 


\subsubsection{Input and display of the payment amount}

The vendor manually enters the price on his keypad (Fig. 5). The traveller's display shows this price. The vendor mentions it to the customer and moves the traveller with his hand towards the customer module (Fig. 6, left). While moving, the screen image rotates, to become readable for the customer. Once the traveller has arrived at the customer module, it stays there (Fig. 6, right). The customer module now seems to have become larger, while the vendor module has shrunk. The visual balance that was established in start mode, is clearly broken.

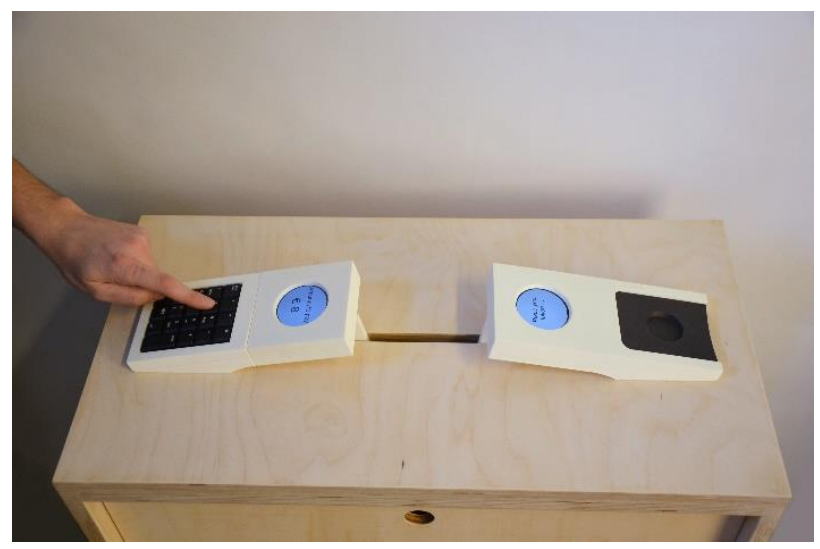

Fig. 5 The vendor enters the price on the keypad of the vendor module
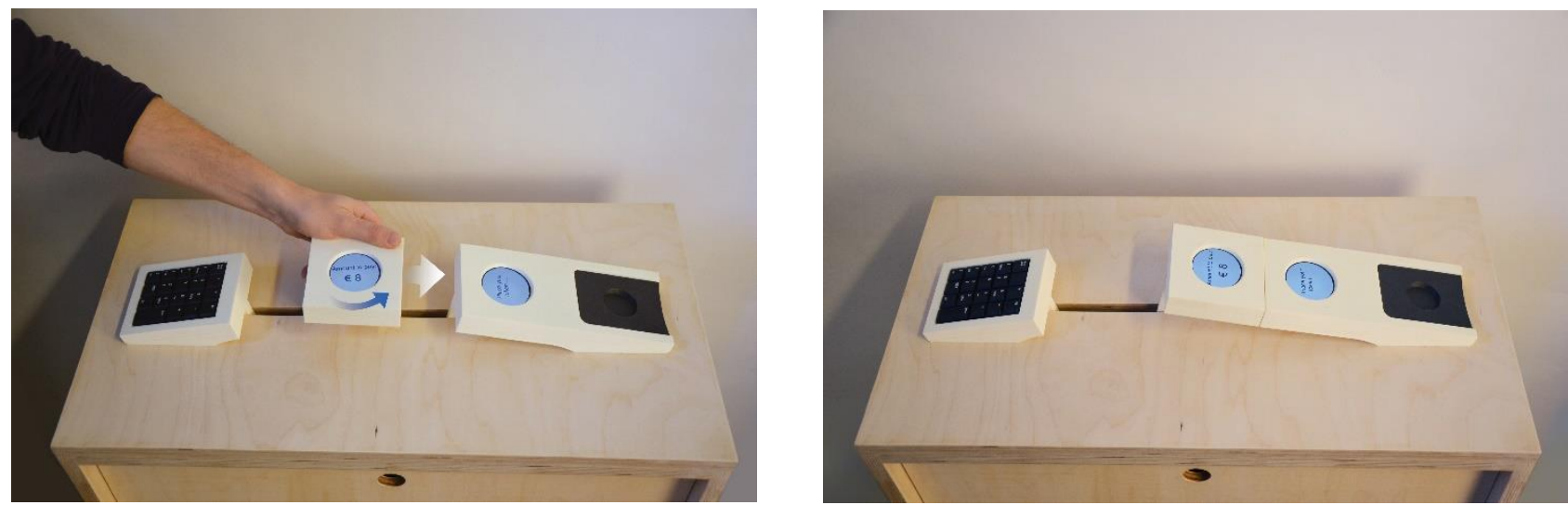

Fig. 6 Left: The vendor moves the traveller towards the customer module, the screen rotates accordingly. Right: The traveller resides at the customer module

\subsubsection{Payment transaction and confirmation}

The customer fetches his token (Fig. 7, left), and places it in the cradle of the customer module (Fig. 7 , right). Out of the token, a green "liquid" rises on the customer display, representing the money on the customer's bank account, and a number, indicating this amount. The customer now sees two circular displays in front of him, one on top of the other. The lower one shows the money on his account, and the upper one displays the price (Fig. 7, right). 

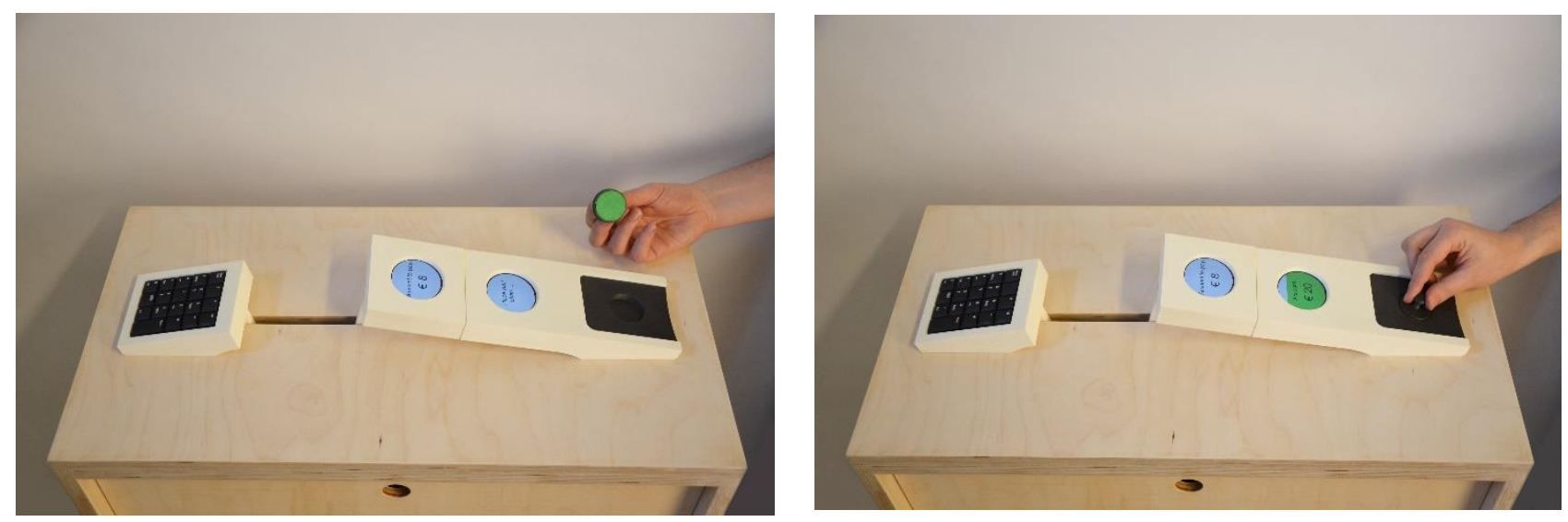

Fig. 7 Left: The customer fetches his token. Right: The token is placed on the customer module

To execute the payment transaction, the customer pushes the slider with the token in the direction of the vendor (Fig. 8, left). The slider slides in, "magically" appears on the customer display, and moves the green liquid forward, into the traveller display with the price. Once the liquid reaches this display, it is injected in it. At the same time, the terminal generates a bell-like sound. After that, the traveller automatically moves back to its original place, at the vendor module (Fig. 8, right). The money literally moves towards the vendor.
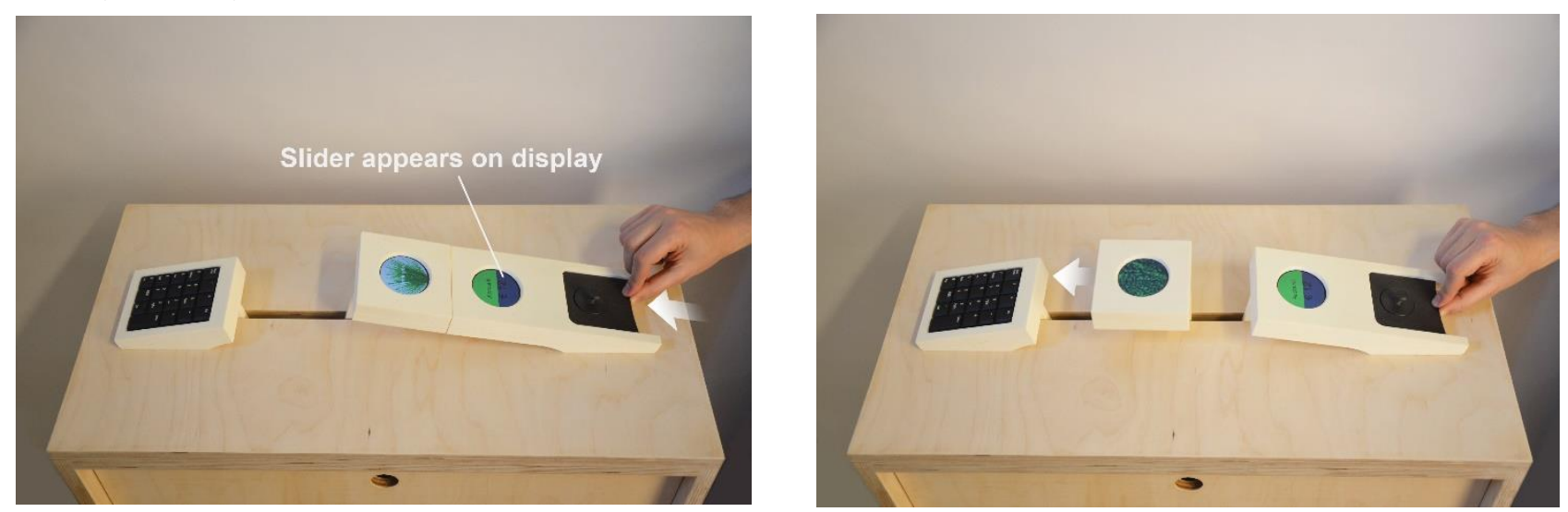

Fig. 8 Left: The customer pushes the slider in the direction of the vendor. Right: The traveller moves towards the vendor

When the traveller reaches the vendor module, its physical movement stops, and is taken over on its display: the green liquid moves "in" the vendor module (Fig. 9, left). At the end of the transaction, the two similar shapes are restored, and so is the visual balance of the whole setting. The traveller display shows a "Payment successful!" message, while the customer display shows a lower liquid level, and a new account status (Fig. 9, right). Finally, the customer takes back his token. 

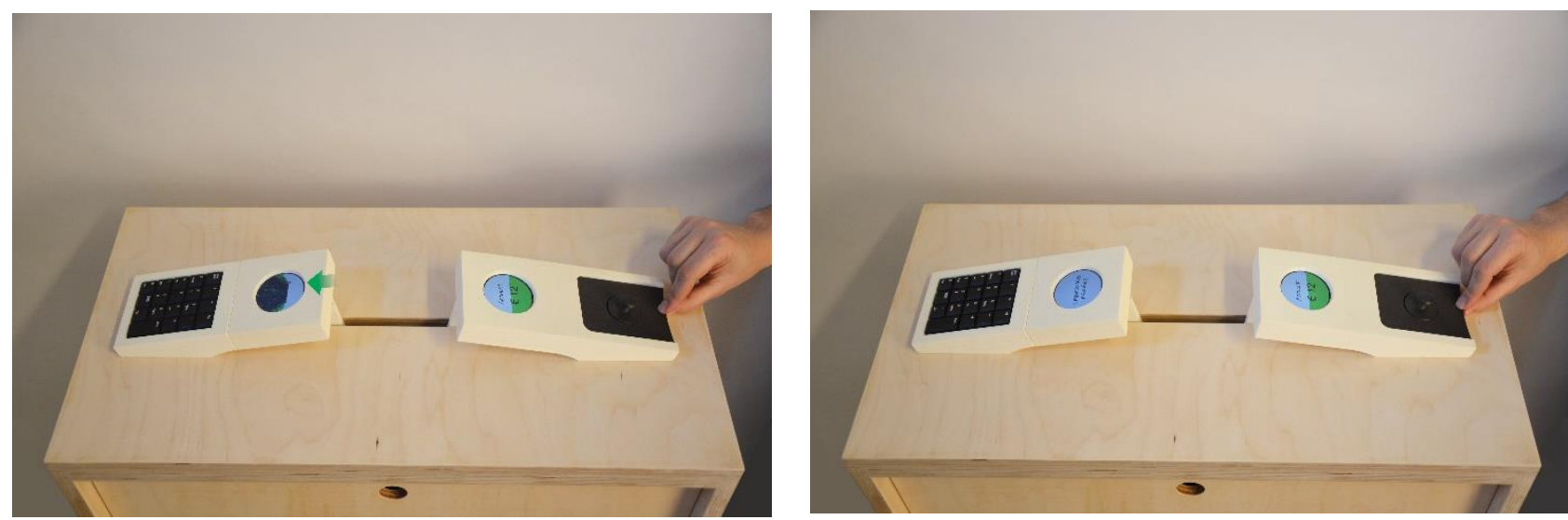

Fig. 9 Left: The green liquid moves "in" the vendor module. Right: The customer display shows a lower liquid level

\subsection{The EPT: an illustration of the third stand}

The EPT was designed in order to further define the third stand. For a detailed report of the design process and design decisions, we refer to Van Campenhout [51]. Subsections 3.3.1 and 3.3.2 provide two theoretical themes that resulted from the design session.

\subsubsection{Building on rich interaction}

The third stand builds on rich interaction [18], a perspective on the design of digital products [43]. While the first stand starts from digital information and how it should be embodied [30, 56], rich interaction starts from the human body, and how the physical world opens up to it as a whole of perceptions and action possibilities. It aims at a unity of form, function and interaction (Fig. 10) by employing meaningful, expressive bodily movements and products that resonate with these movements through physical shape changes.

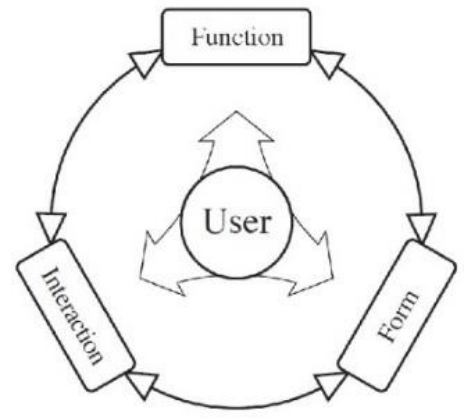

Fig. 10 A unity of form, function and interaction, adapted from [15]

From the very beginning, the EPT was designed for this very unity. We started with the creation of a payment interaction, before thinking about the hardware with which it would be realized [53]. Our initial question was: how do you hand over money that is not physically present? What are meaningful actions to express a transfer of money between two people? In other words, the interaction itself became a design driver, instead of the consequence of a specific hardware setup. Through the whole design process, interaction, form and function were developed concurrently and 
they composed each other. The result is a strong specific interactive product [55], that expresses its functionality: executing a payment transaction between two persons, at a desktop counter in a shop. The legacy of the rich interaction framework is also evident in the use of shape changes. The EPT employs several physical shapes to reflect the state of its processor at each moment in its interaction routine, and to offer different action possibilities to the user. When the terminal is in rest (Fig. 4), the traveller is at the vendor side, and the EPT shows a symmetrical, balanced setup of two equal shapes. When the vendor has moved the traveller towards the customer (Fig. 7 and 8), this symmetry is broken, and the EPT is in payment mode: it is ready to receive money. As soon as the money is injected in the terminal, the original symmetrical shape is restored (Fig. 9).

\subsubsection{The border between the digital and the physical}

Digital payment terminals in general emerged as a result of the dematerialization of cash money. Therefore, we considered them fit for a third stand design approach. The third stand takes dematerialization as a starting point, and aims to consciously guide it. In practice, this means that a third stand design process centres on the position of the border between the physical and the digital. It urges the designer to continuously make judgements and decisions on where in the product this border resides, and which product components are to be re- and dematerialized.

In the design process of the EPT, we explored different embodiments of digital money, through several iterations (Fig. 11): a function-specific physical token, a smart phone, and a representation on a display as a number or a graphical entity. Each of these embodiments centred on a certain degree of dematerialization, or a certain position of the border between the digital and the physical.
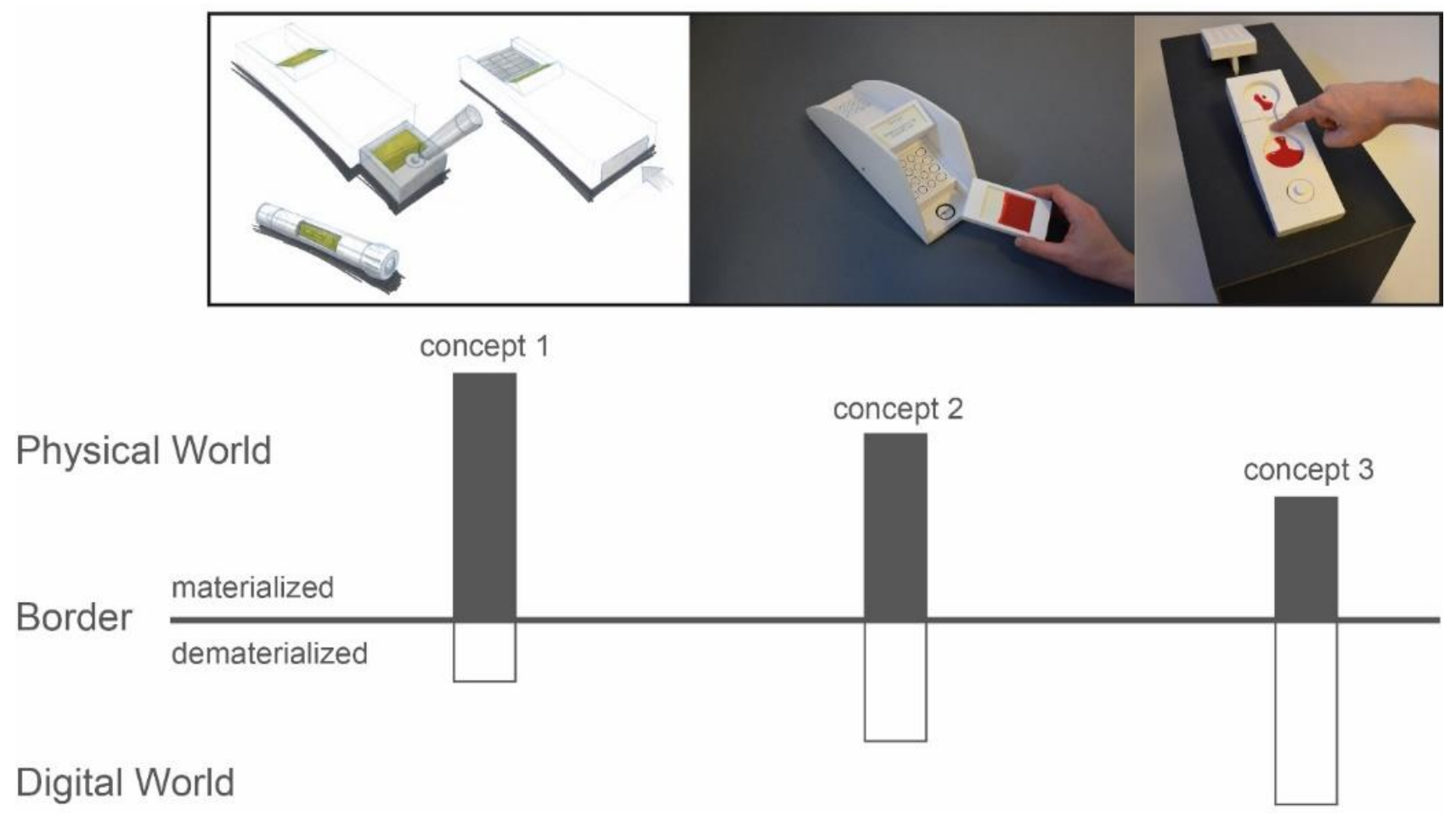

Fig. 11 Left: Embodiment of one's money with a physical token. Middle: Embodiment with a smart phone. Right: Embodiment through representation on a display 
We acknowledge that the idea of balancing the physical and the digital is not new. Several researchers have worked on this topic.

Jetter, Geyer, Schwarz and Reiterer [37] propose Blended Interaction, a framework for the design of interactive spaces. Their design approach does not prefer the physical over the digital, but treats both worlds equally. Blended interaction takes into account our experience with the physical world, but also with digital technology and knowledge that is not rooted in the physical world. For example, people have firmly internalized multi-touch interactions - touch, slide and pinch gestures so as to expect each digital screen to be touch-sensitive. Jetter et al. [37] claim that designers should make use of this knowledge, just like they should leverage our familiarity with the physical world. This way, Jetter et al. propose a nuanced balance of the physical and the digital.

Their framework is elaborated further by Hurtienne and Israel [33], who present so-called PIBADIBA lists (Physical Is Better At - Digital Is Better At) that sum up the strengths and weaknesses of both the physical and the digital, in order to assist the designer in creating and evaluating a blended interaction system.

Hornecker [29] nuances the canonical idea of familiarity in embodied interaction. She states that leveraging user's knowledge from the real world does not necessarily improve an interface's intuitiveness. Designers of digital systems should be aware of this and re-materialization should not be considered as a goal in itself.

However, we believe that the third stand provides a different understanding of this balance. We discuss this in the upcoming sections.

\section{Experiment}

In a previous publication [55], we suggested that the added value of the third stand should not be sought in usability and pragmatism, but rather in the wider area of user experience. In more recent research, we have tried to make this claim more precise by conducting a laboratory experiment [39], in which we compared the EPT with an exponent of the second stand, or current generation of payment terminals. In the following sections, we describe our experiment, its theoretical foundations and its results.

\subsection{Background: User experience}

Our experiment contains variables like Pragmatic Quality, Hedonic Quality, need fulfilment and Positive Affect. These variables emerge from Marc Hassenzahl's theory of user experience. We briefly describe it here.

\subsubsection{Product evaluation}

An interactive product has features [22], like shape, colour, interaction style and functionality. These features are perceived by the user, and combined with his expectations and standards. This way, the user grants a series of attributes to this product. An attribute can be: elegant, handy, surprising, challenging, useful. Attributes are partly personal constructs, and therefore partly 
subjective: a product that is surprising to a particular user, can be boring to another, more experienced user. Hassenzahl [22] distinguishes two groups of product attributes: pragmatic and hedonic attributes.

Pragmatic attributes concern the utility and usability of a product. They are instrumental, i.e. they refer to a judgment of the product's ability to fulfil a behavioural, or do-goal. Typical pragmatic attributes of an interactive product can be: helpful, efficient, fast, easy-to-use.

Hedonic attributes [7] emphasize the realization of the user's psychological well-being. They are related to what Hassenzahl calls be-goals, and refer to a judgment of "the product's potential to support pleasure in use and ownership" [26], i.e. to be admired, to be stimulated.

A bundle of hedonic and pragmatic attributes form the product's character. Using a product with a certain character, in a certain context, leads to consequences [23]: emotions, evaluations and behaviour. Typical examples of evaluative values are beauty and goodness. While the product's attributes are considered substantive and low-level, i.e. inherently sticking to the product itself, evaluative values are considered to be verdictive, high-level constructs, determined by the product's attributes, and the user's personality. A sports car can look masculine and able (attributes), and can still be judged as ugly (evaluative construct).

\subsubsection{Positive affect as a consequence of need fulfilment}

Sheldon, Elliot, Kim, and Kasser [46] defined 10 universal psychological needs, and explored their relationship with positive affect (experienced emotions), in the context of satisfying events. The 10 needs are listed and explained in Table 1, copied from Sheldon et al. [46]. They found that the degree of fulfilment of one or more needs was positively related to the intensity of positive affect. In other words, need fulfilment leads to positive experience [24, 44]. Moreover, the 10 needs can be distinguished as independent from each other, as they cause different positive experiences. Therefore, a classification of experiences becomes possible.

Hassenzahl [24] built on Sheldon's theory, and related it to positive experiences with interactive products. He showed that interactive products that fulfil one or more needs, generate positive emotions. Moreover, he explored the link between need fulfilment, positive affect and the abovementioned product attributes, pragmatic and hedonic quality. He found that hedonic quality was stronger related to need fulfilment and positive affect than pragmatic quality. Therefore, pragmatic quality is considered as an instrumental necessity of a product, but not as a source of pleasure in itself. In other words, a product that is unnecessarily ineffective and inefficient is a bad product. A product that is effective and efficient, is not necessarily considered as a good product. To be evaluated as good, the product has to fulfil one or more needs, and create a positive experience. It can do this, if it contains hedonic quality. 


\begin{tabular}{|c|c|}
\hline Need & Description \\
\hline Autonomy-Independence & $\begin{array}{l}\text { Feeling like you are the cause of your own actions rather than feeling that external forces or } \\
\text { pressure are the cause of your action }\end{array}$ \\
\hline Competence-effectance & $\begin{array}{l}\text { Feeling that you are very capable and effective in your actions rather than feeling } \\
\text { incompetent or ineffective }\end{array}$ \\
\hline Relatedness-belongingness & $\begin{array}{l}\text { Feeling that you have regular intimate contact with people who care about you rather than } \\
\text { feeling lonely and uncared of }\end{array}$ \\
\hline Influence-popularity & $\begin{array}{l}\text { Feeling that you are liked, respected, and have influence over others rather than feeling like a } \\
\text { person whose advice or opinion nobody is interested in }\end{array}$ \\
\hline Pleasure-stimulation & $\begin{array}{l}\text { Feeling that you get plenty of enjoyment and pleasure rather than feeling bored and } \\
\text { understimulated by life }\end{array}$ \\
\hline Security-control & $\begin{array}{l}\text { Feeling safe and in control of your life rather than feeling uncertain and threatened by your } \\
\text { circumstances }\end{array}$ \\
\hline Physical thriving-bodily & $\begin{array}{l}\text { Feeling that your body is healthy and well-taken care of rather than feeling out of shape and } \\
\text { unhealthy }\end{array}$ \\
\hline Self-actualizing-meaning & $\begin{array}{l}\text { Feeling that you are developing your best potentials and making life meaningful rather than } \\
\text { feeling stagnant and that life does not have much meaning }\end{array}$ \\
\hline Self-esteem-selfrespect & $\begin{array}{l}\text { Feeling that you are a worthy person who is as good as anyone else rather than feeling like a } \\
\text { "loser" }\end{array}$ \\
\hline Money-luxury & $\begin{array}{l}\text { Feeling that you have plenty of money to buy most of what you want rather than feeling like a } \\
\text { poor person who has no nice possessions }\end{array}$ \\
\hline
\end{tabular}

Table 1 The 10 universal needs, adapted from Sheldon et al. [46]

\subsection{Comparative experiment}

We compared the EPT with Worldline's XENTA Contactless Reader (https://worldline.com), an existing payment terminal, which we call henceforth the Commercial Payment Terminal (CPT). We give a short description of its payment routine. A video of this routine can be found on https://www.youtube.com/watch?v=_tYsT3OW6iM

\subsubsection{Input and display of the payment amount}

The XENTA platform has many configurations, but in our experiment, it comprised two physically separated modules: a customer module and a vendor module. The vendor manually enters the price on the keypad of the vendor module. This price appears on its display, as well as on the display of the customer module (Fig. 12, left).

\subsubsection{Payment transaction}

The customer takes his payment card, and holds it close to the NFC sign. A beeping sound is heard, and the display of the customer module shows the messages "Payment accepted" and "Thank you for shopping" (Fig. 12, right).

\subsubsection{An exponent of the second stand}

The XENTA customer module is an exponent of the second stand, since its interaction routine is a standardized one. It was not designed to embody the meaning of a payment interaction, and as such, 
it does not express the functionality that it opens. This standardized interaction routine is reflected in the XENTA's overall shape and layout, which is approached as packaging, rather than as carrier of meaning and expressiveness [19].
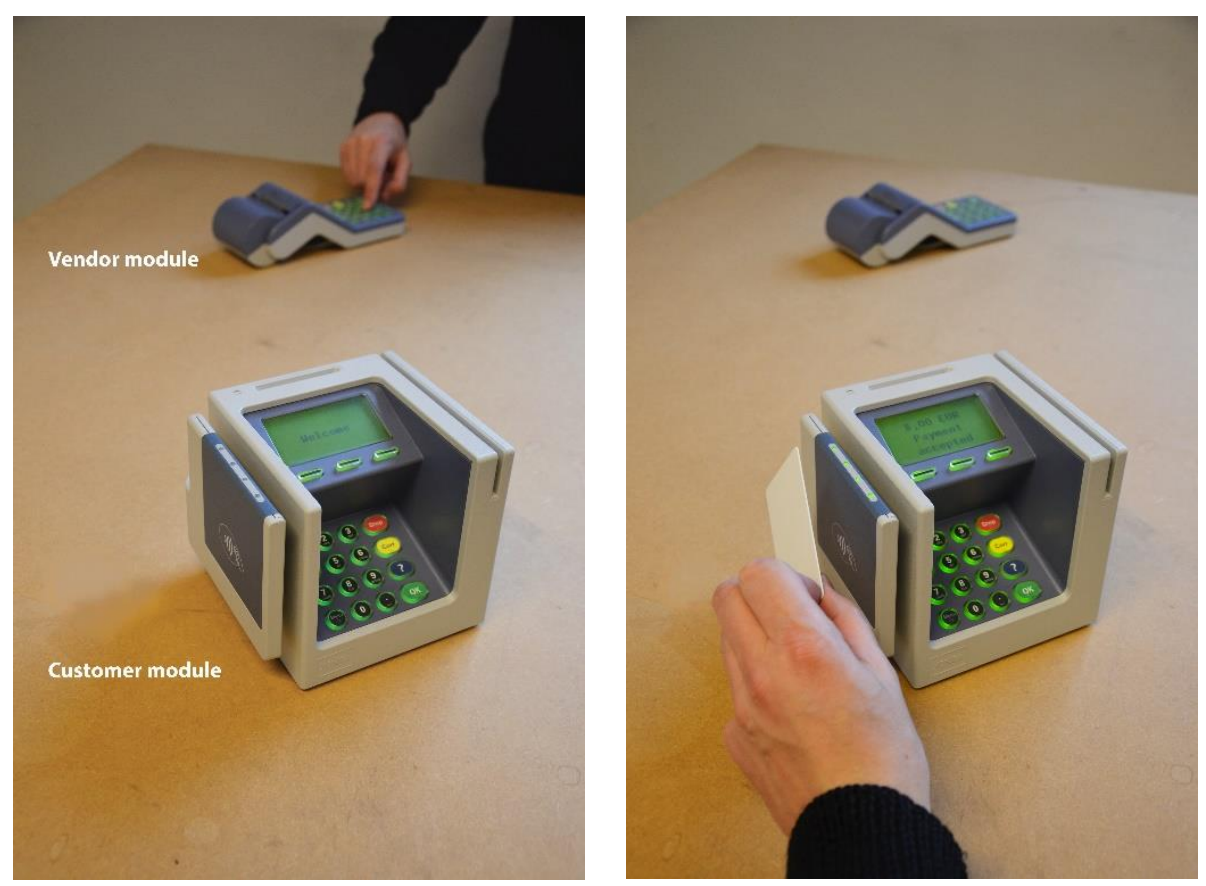

Fig. 12 Left: The vendor enters the price on the keypad of the vendor module. Right: The customer holds his payment card close to the NFC sign on the customer module

\subsection{Data collection}

We organized three experiments with a within subject design, all of them following a similar pattern, and making use of the same questionnaires [52]. Their practical setup however differed. In chronological order:

- An online experiment that offered an imagined experience [5, 6] (50 participants). Both purchase and payment interactions were presented with 2 movies.

- A physical experiment with a real experience (25 participants). The participants entered 2 simulated shops, and pretended to buy a bottle of wine. Since the physical experiment was the only one that tested a real experience, we consider it as the most important one.

- A vendor experiment with an imagined experience (25 participants). Both purchase and payment interactions were presented with 2 movies. The participants were vendors and shop owners.

In the context of this paper, we focus on the physical experiment and its results, since they are representative for the results of the two other experiments.

The 25 participants in the physical experiment were recruited through staff members of the University of Antwerp and had no prior knowledge of the system. 9 participants were male, 16 female. The sample's median age was $44($ Minimum $=25$, Maximum $=68)$.

The experiment contained 2 parts: a quantitative and a qualitative part. We discuss each part separately. 


\subsubsection{Quantitative part}

The quantitative part compared the CPT and the EPT. The participants were asked to complete, for each payment terminal, 3 questionnaires. These questionnaires, and how we customized them, can be found in the supplementary material of this paper.

- A Dutch version of the PANAS questionnaire for affect [16], investigating 2 dependent variables: Positive Affect (PA) and Negative Affect (NA). Both variables are captured with 10 items.

- A customized version of the Needs questionnaire for need fulfilment [24, 46]. We investigated 6 needs, providing 6 dependent variables: autonomy, competence, relatedness, stimulation, security and self-esteem. Each need is captured with 3 items.

- A customized version of the AttrakDiff 2 questionnaire for product evaluation [25]. This questionnaire investigates 3 dependent variables: Pragmatic Quality (PQ), Hedonic Quality (HQ) and General Product Evaluation (GPE). Each variable is captured with 4 items.

Each questionnaire contained a series of Likert scales.

We formulated 11 testable hypotheses, based on the 11 variables above $(3+6+2)$. They are listed in Table 2.

Table 2 The 11 hypotheses

\begin{tabular}{|c|c|c|c|c|}
\hline $\mathrm{H} 1$ & The EPT scores higher on Positive Affect than the CPT & $P A_{E P T}>P A_{C P T}$ & accepted & $p<0.005$ \\
\hline $\mathrm{H} 2$ & The CPT scores higher on Negative Affect than the EPT & $N A_{E P T}<N A_{C P T}$ & rejected & n.s. \\
\hline $\mathrm{H} 3$ & The EPT scores higher on autonomy than the CPT & Autonomy $y_{E P T}>$ Autonomy $_{\text {CPT }}$ & rejected & n.s. \\
\hline $\mathrm{H} 4$ & The EPT scores higher on competence than the CPT & Competence $_{\text {EPT }}>$ Competence $_{\text {CPT }}$ & excluded & inconsistent \\
\hline $\mathrm{H} 5$ & The EPT scores higher on relatedness than the CPT & Relatedness $\mathrm{EPT}_{\mathrm{EP}}>$ Relatedness $_{\mathrm{CPT}}$ & rejected & n.s. \\
\hline $\mathrm{H} 6$ & The EPT scores higher on stimulation than the CPT & Stimulation $_{\mathrm{EPT}}>$ Stimulation $_{\mathrm{CPT}}$ & accepted & $\mathrm{p}<0.01$ \\
\hline $\mathrm{H} 7$ & The EPT scores higher on security than the CPT & Security $_{E P T}>$ Security $_{C P T}$ & excluded & inconsistent \\
\hline $\mathrm{H} 8$ & The EPT scores higher on self-esteem than the CPT & Self-esteem $\mathrm{EPT}_{\mathrm{ET}}>$ Self-esteem $\mathrm{CPT}_{\mathrm{CP}}$ & excluded & inconsistent \\
\hline $\mathrm{H} 9$ & The CPT scores higher on Pragmatic Quality than the EPT & $P Q_{E P T}<P Q_{C P T}$ & accepted & $\mathrm{p}<0.01$ \\
\hline $\mathrm{H} 10$ & The EPT scores higher on Hedonic Quality than the CPT & $H Q_{E P T}>H_{C P T}$ & accepted & $p<0.0005$ \\
\hline H11 & The EPT scores higher on General Product Evaluation than the CPT & $\mathrm{GPE}_{\mathrm{EPT}}>\mathrm{GPE}_{\mathrm{CPT}}$ & accepted & $\mathrm{p}<0.01$ \\
\hline
\end{tabular}

\subsubsection{Qualitative part}

The qualitative part comprised a questionnaire, in which the participants answered a series of 9 questions, of which 7 open and 2 closed. This questionnaire can be found in the supplementary material of this paper. The idea was that the answers would provide insight in the participants' reasoning behind the quantitative data.

\section{Results}

\subsection{Results of the quantitative part}

For the 11 variables, internal consistency was measured by calculating Cronbach's alpha. The results are shown in Table 3. As a rule of thumb, a variable is consistent when Cronbach's alpha is 0.70 or higher [57]. For Pragmatic Quality, Cronbach's alpha was 0.665 on one condition and 0.871 
on the other (Table 3). Following Van Wijk [57], we judged this variable to be consistent. 3 variables were inconsistent, and excluded from further analysis: competence, security and selfesteem (Table 2). For the 8 dependent variables that proved consistent, a paired $t$ test was applied on each pair of mean values. A significance level of .05 was adopted. 5 variables provided significant results (Table 2): Positive Affect, stimulation, Pragmatic Quality, Hedonic Quality and General Product Evaluation. We discuss each of them separately. The results of the 3 variables that were non-significant, are presented in the supplementary material of this paper.

Table 3 Cronbach's alpha for each dependent variable

\begin{tabular}{|l|c|c|c|}
\hline Category & N of Items & $\begin{array}{c}\text { Cronbach's } \\
\text { Alpha CPT }\end{array}$ & $\begin{array}{c}\text { Cronbach's } \\
\text { Alpha EPT }\end{array}$ \\
\hline Positive affect & 10 & 0,906 & 0,884 \\
\hline Negative affect & 10 & 0,844 & 0,756 \\
\hline Autonomy & 3 & 0,805 & 0,863 \\
\hline Competence & 3 & 0,546 & 0,100 \\
\hline Relatedness & 3 & 0,743 & 0,747 \\
\hline Stimulation & 3 & 0,869 & 0,803 \\
\hline Security & 3 & 0,615 & 0,618 \\
\hline Self-esteem & 3 & 0,831 & 0,174 \\
\hline Pragmatic Quality & 4 & 0,665 & 0,871 \\
\hline Hedonic Quality & 4 & 0,859 & 0,791 \\
\hline General Product Evaluation & 4 & 0,828 & 0,812 \\
\hline
\end{tabular}

\subsubsection{Affect and need fulfilment}

\subsubsection{Positive Affect}

Hypothesis 1 (Table 2) was accepted. The data showed that the EPT scored higher on Positive Affect than the CPT (Fig. 13, left). The participants felt more enthusiastic, active and alert (PA items) when using the EPT than when using the CPT.

Hypothesis 2 (Table 2) was rejected. No relationship was found between Negative Affect and the two terminals. 


\subsubsection{Stimulation}

Hypothesis 6 (Table 2) was accepted. The EPT fulfils the need for stimulation more than the CPT (Fig. 13, right). This means that the participants perceived the EPT as a device that provides a new, stimulating experience and a pleasurable action routine.
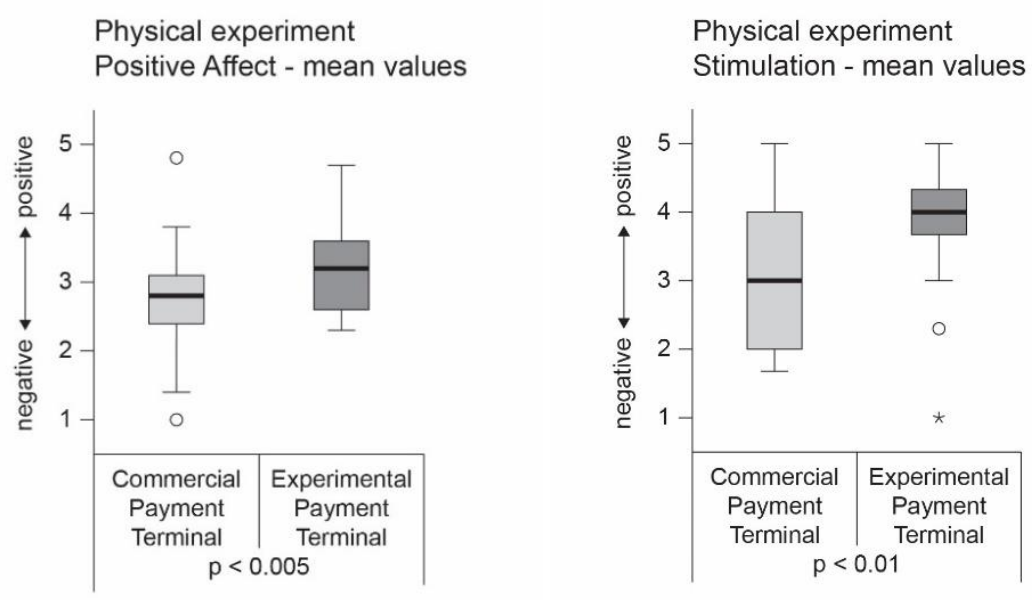

Fig. 13 Left: Results for Positive Affect. Right: Results for stimulation

\subsubsection{Autonomy and relatedness}

Hypotheses 3 and 5 (Table 2) were rejected. No relationship was found between autonomy or relatedness and the two terminals.

\subsubsection{Product perception and evaluation}

\subsubsection{Pragmatic Quality}

Hypothesis 9 (Table 2) was accepted. The CPT scored higher on Pragmatic Quality (Fig. 14, left). The CPT was perceived as more practical, clearly structured, predictable and simple (the 4 PQ items) than the EPT.

\subsubsection{Hedonic Quality}

Hypothesis 10 (Table 2) was accepted. Hedonic Quality turned out to be a salient variable. The EPT scored higher on Hedonic Quality than the CPT (Fig. 14, right). The EPT was found to be more captivating, stylish, premium and creative (the 4 HQ items) than the CPT.

\subsubsection{General Product Evaluation}

Hypothesis 11 (Table 2) was accepted. The EPT scored higher on General Product Evaluation (Fig. 15). The participants judged the EPT as more attractive, better, more pleasant and more motivating (the 4 GPE items). 
Physical experiment

Pragmatic Quality - mean values

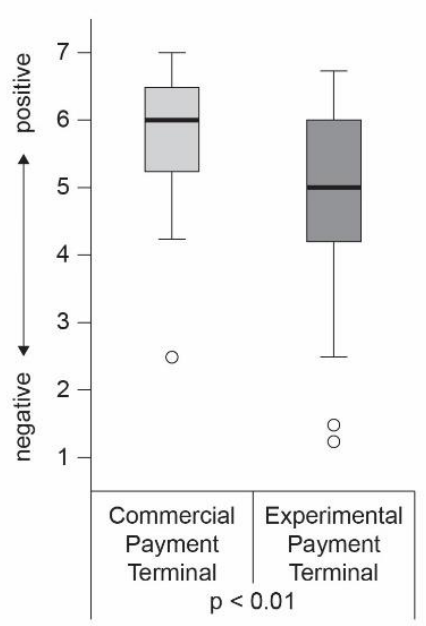

Physical experiment

Hedonic Quality - mean values

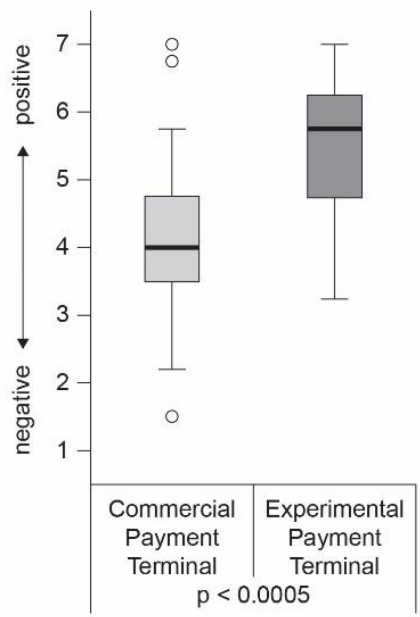

Fig. 14 Left: Results for Pragmatic Quality. Right: Results for Hedonic Quality

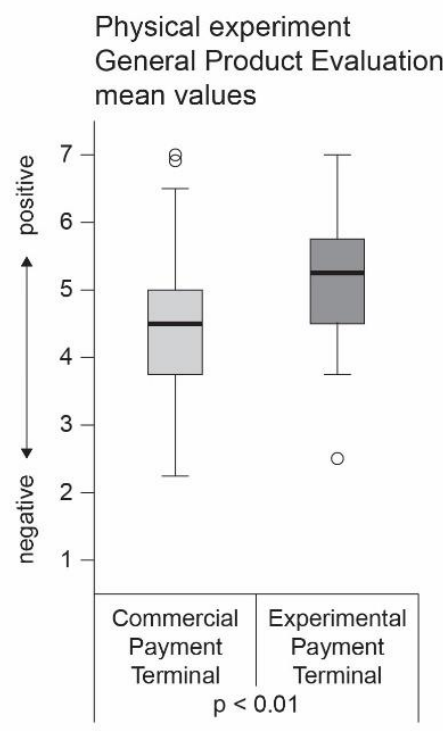

Fig. 15 Results for General Product Evaluation

\subsubsection{Quantitative part: discussion}

The EPT scored higher on Hedonic Quality than the CPT. The EPT was found to be the more captivating and creative terminal (HQ items). This is in line with the EPT's higher score on General Product Evaluation and Positive Affect. The EPT was found to be the better, more attractive, motivating terminal (GPE items), and it made the participants enthusiastic, active and alert (PA items). Moreover, the participants expressed that the EPT provided a new, stimulating and likable payment routine. Given the established link between need fulfilment and Positive Affect (described 
in Subsection 4.1.2), we suggest that the EPT's higher score on Positive Affect is caused by this fulfilment of the need for stimulation.

The CPT scored higher on Pragmatic Quality. The CPT is the more practical, clearly structured, simple and predictable terminal (PQ items). We want to delve deeper into this result. We designed the EPT from the background of rich interaction, i.e. with a focus on regaining some of the rich values of the physical world. As discussed in Subsection 2.1.1, it is generally assumed that the main reason to employ real-world based interaction with digital systems, centres on the concept of familiarity: when digital products are designed in such a way that they capitalize on our skills with the physical world, our interaction with them becomes more natural and intuitive. Naturalness and intuitiveness are often used in the context of ease-of-use, and thus pragmatic usability [2, 3, 24]. As such, they have a pragmatic taste. Our experiment however does not support this rationale: the EPT, designed to re-materialize the payment process, is not perceived as the more pragmatic device. In the case of the EPT, physical embodiment did not lead to a more intuitive interaction. The more simple and predictable terminal is the CPT, in spite of its text-based interaction and overall computer-like appearance.

\subsection{Results of the qualitative part}

The answers to the 2 closed questions were simply counted. The answers to the 7 open questions were divided in different topics and quotes, upon which a conventional content analysis was executed [32]. All results can be found in the supplementary material of this paper. Here, we present the questions that generated the most striking information.

\subsubsection{Which payment terminal is the most pleasurable / agreeable? Which payment terminal do you prefer?}

When explicitly asked which payment terminal was the most pleasurable, the majority of the participants chose the EPT. When asked which terminal they preferred, the majority chose the CPT (Fig. 16, left and right).

This advances a somewhat nuanced image: both terminals more or less generate an equal appreciation. The preference for the EPT, that appeared in the quantitative experiment as a result of General Product Evaluation, is somewhat dimmed in the qualitative experiment. 

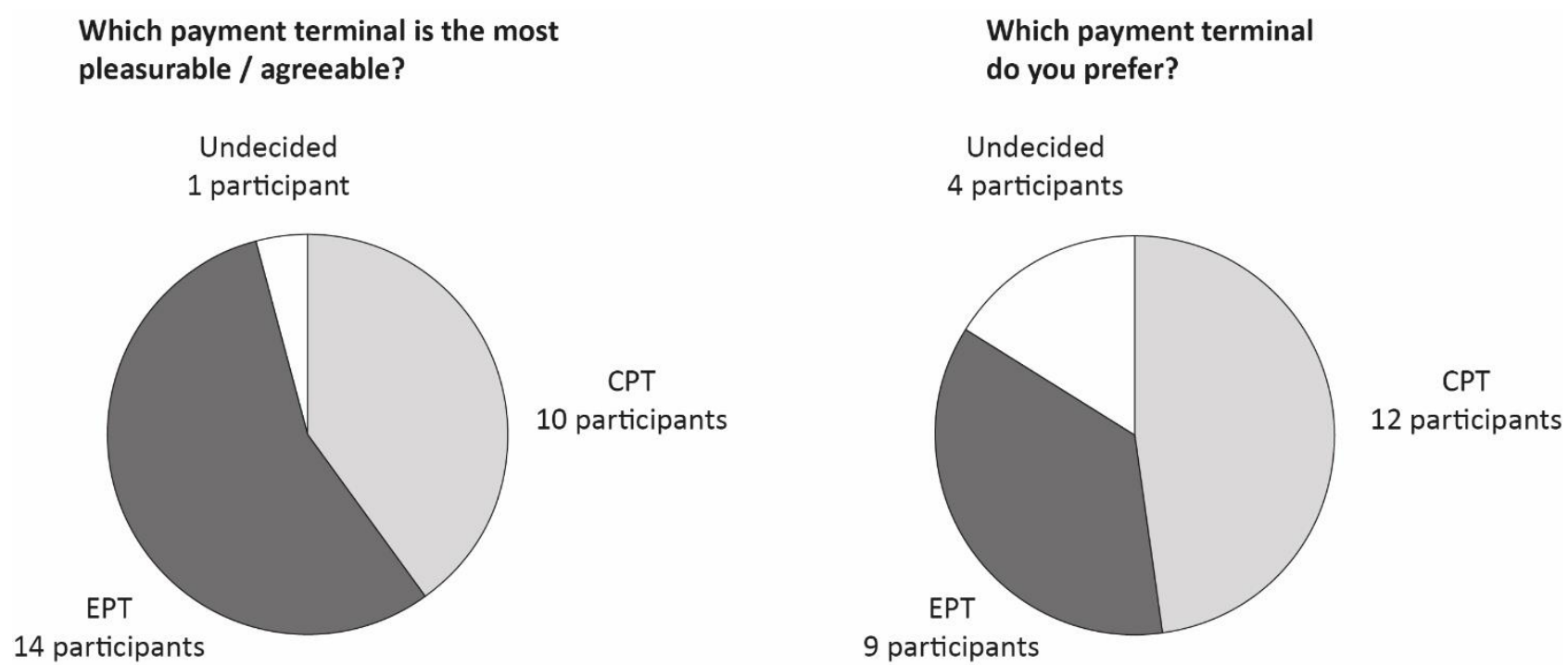

Fig. 16 Left: The majority of the participants chose the EPT as the most pleasurable device. Right: The majority of the participants preferred the CPT

\subsubsection{What did you like most about the CPT? What did you like most about the EPT?}

Tables 4 and 5 show which terminal characteristics were mentioned the most. It is clear that the CPT was valued mostly for its speed, handiness and for the fact that the participants were already familiar with the device. The EPT was valued for its originality and innovativeness. The participants mentioned the fact that the EPT generates a feeling of control and transparency, and that it makes you "feel" the payment interaction. It makes the payment interaction more visible and tangible.

Table 4 Most frequently mentioned terminal characteristics for the CPT

\begin{tabular}{l} 
What do you like the most about the CPT? \\
Speed, the terminal demands few actions. \\
\hline Handiness, the terminal demands simple actions. \\
\hline The terminal is known, it feels familiar. \\
\hline
\end{tabular}

Table 5 Most frequently mentioned terminal characteristics for the EPT

\begin{tabular}{|l|}
\hline What do you like the most about the EPT? \\
The terminal is original / creative / innovative \\
\hline Feeling of control / transparency / clear organization / clarity \\
\hline The payment transaction is visible / tangible. You can "feel" the payment transaction.
\end{tabular}

5.2.3 In what kind of shop would you situate the CPT? In what kind of shop would you situate the EPT?

The CPT was situated mainly in the supermarket, or large shopping mall (Table 6), while EPT was situated in trendy, stylish shops, and in expensive shops (Table 7).

Both terminals were situated in retail shops with low prices and fast service (Table 6 and 7). As far as the fast and handy CPT concerns, this is not surprising. But what is the connection between retail shops and the EPT? Our suggestion for an explanation is that the butcher, the bakery and the 
neighbourhood store were considered by the participants as places that they frequently visit, and where personal contact with the vendor plays a role. This personal contact would fit the EPT better than the CPT.

Table 6 Most mentioned shops for the CPT

In what kind of shop would you situate the CPT?
Supermarket / shopping mall
Retail trade (low prices and fast service): bakery / butcher / neighbourhood store / ...

Table 7 Most mentioned shops for the EPT

\begin{tabular}{|l|}
\hline In what kind of shop would you situate the EPT? \\
Trendy, stylish shops, where the shopping experience matters. \\
\hline Expensive shops: jewelry / fashion / luxury \\
\hline Retail trade (low prices and fast service): bakery / butcher / neighbourhood store / ... \\
\hline
\end{tabular}

\subsubsection{Qualitative part: discussion}

In general, the results of the qualitative experiment support the results of the quantitative experiment. In the qualitative experiment, the CPT's speed and handiness are found to be its most important assets, and the participants situated the CPT mainly in supermarkets and large shopping malls, places where efficiency and effectiveness are important. This is in line with the CPT's high score on Pragmatic Quality in the quantitative experiment. Moreover, in the quantitative experiment, we saw that the major benefit of the EPT over the CPT was found in the EPT's hedonic quality, and fulfilment of the need for stimulation. We suggested that the latter caused its higher score on Positive Affect. This also came up in the qualitative experiment, where the EPT turned out to be the more creative and pleasurable terminal, that preferably would be installed in exclusive and fashionable shops. One could ask the question how long-lasting this hedonic quality and stimulating experience really is. Once the user is used to it, how much remains of the initial experience? Or, as Hassenzahl et al. state it, "stimulation is based on the ever new, and thus implies short-lived consumption" [27].

However, Subsection 5.2.2 also presents new elements: the EPT seems to generate a more complex experience than a one-dimensional stimulating one. Other assets, different from its possibly superficial appeal, seem to appear.

First, the EPT was said to give a clear visual overview of the payment transaction, and, for the customer, generate a sense of "being-in-control". Next, the EPT was experienced as making the payment routine more tangible and approachable, as opposed to the CPT, resulting in a feeling of "having paid". Participants reported, often in expressive phrases, that they felt that the EPT approached the payment process more physically, human, and sensually. They could "feel" the money flow from them towards the vendor. They had the feeling of literally "handing over" something, and doing this in a conscious way. Note that this asset was only detected in the qualitative experiment, and not in the quantitative one.

We suggest that both elements, being-in-control and tangibility, provide additional explanation for the EPT's higher score on General Product Evaluation and Positive Affect. 


\section{Discussion}

\subsection{Pragmatic values versus hedonic values}

We reconsider the rationale behind the first stand, as described in Subsection 2.1.1. This rationale starts from our familiarity with the physical world. The aim is to design digital products and systems that capitalize on this familiarity and as such involve an interaction that is more intuitive and natural. This argumentation starts from a desire for digital products to be easy to use. This desire is a pragmatic, functional one. It measures interaction quality in terms of the fulfilment of a functional goal. In order to attain this goal, the physical world and its affordances are brought in.

In contrast to this rationale, our experiment showed that the more tangible, re-materialized terminal, the EPT, scored lower on Pragmatic Quality than the more traditionally-interfaced CPT. Moreover, the EPT scored higher on Hedonic Quality. A decade ago, Frens [18] compared different digital cameras, one of which offered rich action controls. He came to a similar conclusion: the camera offering rich interaction did not score higher on Pragmatic Quality than a camera with conventional button controls. On the other hand, the participants found the rich actions camera more beautiful.

From the findings of our experiment, we conclude that an embodied design approach does not necessarily evoke pragmatic values, and can lead to hedonic values. We believe that this is an essential element to define the third stand: the third stand employs re-materialization from a hedonic perspective. Here lies the answer to our research question, and the contribution of the third stand to the embodied interaction research agenda. What is the added value of the third stand? The third stand shows that the reason to choose for embodied interaction, should not uniquely be sought in pragmatism or ease-of-use, but can be found in the realm of hedonic values. This is in line with Dourish [11] who states that a design perspective on embodied interaction should seek to find a new relation between the product and its user, one that transcends the traditional idea of the user interface, and reaches into the more holistic user experience. We position the third stand as such a design perspective.

Fig. 17 illustrates the presented concepts: the second stand adheres to dematerialization, while the first and the third stand follow a re-materialization path. The first stand does this for pragmatic reasons, as opposed to the third stand, which attaches importance to hedonic values.
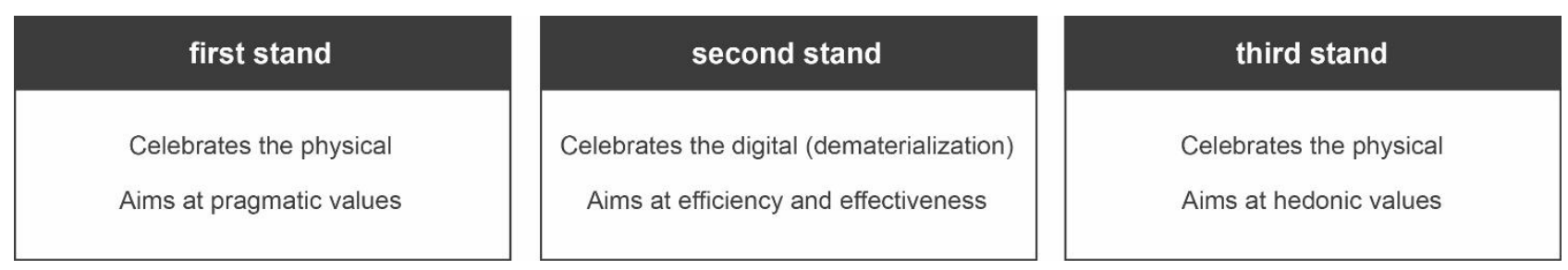

Fig. 17 The characteristics of the first, second and third stand

\subsection{Limitations of the experiment}

The setup of the experiments might have biased the results. We see four possible biases.

First, we should bear in mind that the form factor of the CPT, and the fact that it involves a payment card, was something that all participants were familiar with. Moreover, when the experiment took place, the XENTA terminal was widely used in the Benelux. To what extent did this influence the 
experiment's results? It is hard to adequately answer this question. The qualitative experiment clearly proved that this familiarity played a role, and mostly favored the CPT above the EPT. On the other hand, it did not prevent the EPT to score better on Positive Affect, stimulation, Hedonic Quality, Global Product Evaluation, being-in-control and tangibility.

Second, the EPT clearly is a prototype, while the CPT is a mass product. In this case we do not refer to the fact that the CPT is widely known as opposed to the EPT, but rather to the fact that it has already proven itself in the real world. Our suggestion is that this achievement lends the CPT an image of reliability and trustworthiness and thus influences the results of the experiment.

Third, in none of the three experiments, the participants executed a real payment with their own money. They only acted as if they purchased something, in an artificial, neutral context. This might have influenced some of the experiment's outcome. At this moment, it is difficult to assess the importance of this influence [39].

Finally, although both terminals were presented in the same way, it must have been clear that the experiment was testing the EPT rather than the CPT. In that case the participants might have wanted to please the experimenter, and tell him what he or she liked to hear. This bias, the so-called social desirability bias [15], might have played a role in our experiment, since the experimenter was actively involved in it.

\section{Reflection}

In the remaining part of this paper, we try to get a better understanding of the hedonic values that the third stand aims at. In Subsection 7.1, we reframe the characteristics of the physical world, and, in 7.2, we sketch the specific value system of the third stand.

\subsection{About physical limitations}

For a reflection on the hedonic values of the third stand, we believe a different articulation of the characteristics of the physical world provides handles. What if, for now, we stop considering the physical world as a whole of action possibilities, or the home base of physical richness? What if we start thinking of it as a whole of limitations? After all, if we look at the physical world from the viewpoint of the digital world, its properties that we feel familiar with, become limitations. Let us explain.

- The physical world is tangible, but it is also mainly persistent, rigid and changeless. Most of the time, the objects in the physical world do not suddenly disappear and reappear [33]. They keep their shape, and are unique. In the digital world, objects have a more dynamic nature: they continuously pop up and vanish. Their shape is changeable, and they can be duplicated or deleted at will.

- The course of events in the physical world has a certain inertia and slowness. Every movement in the physical world has to overcome gravity and friction, and therefore demands time and effort. Events and movements in the digital world happen without effort, in a split second, caused by the slightest touch of your finger. 
- Physical objects are vulnerable, as they are prone to age and wear. If we value them, we have to treat them with care. Digital objects are infinitely reproducible and do not gather traces from age and use [42]. Every time we call for them, they look and feel bright new, and as such, less delicate and vulnerable.

If we consider the physical world as a whole of limitations, then the beauty of the digital -and of dematerialization- lies in the fact that it helps us to overcome these physical limitations. The digital provides us with super powers [36].

Now let us turn things around, and see the digital as a source of richness, so abundant that it threatens to flood us [58]. The limitations of the physical world are not anymore something we want to overcome, and be freed from. Instead they become a blessing, a protection against the unbridled freedom and limitless possibilities of the digital. By re-materializing, we then impose these limitations on the digital world. In other words, we choose to deliberately limit the digital world, or design for digital limitations.

The EPT is an example of designing for digital limitations. A physical payment transaction with cash money usually happens between two persons. Due to the persistent nature of coins and bills, they have to be carefully counted and handed over from one person to the other, both consciously attending to the process, which can take a substantial amount of time. When we designed the Experimental Payment Terminal (EPT), we started from the idea of a person that physically hands over an amount of coins and bills to another person. This eventually materialized in the physical layout of the EPT, and the idea of the traveller that moves back and forth between two fixed stations. The concept of displaying both the payment amount and the customer's bank account stems from the same basic idea. The payment transaction on the EPT consists of different physical actions and the overall time it takes, is substantial. We chose the movement of the traveller to be slow, mainly for aesthetic reasons, but a side effect of this choice is that the customer gets the chance to consciously realize what he is doing, and why he is doing it. The act of payment becomes more prominent, and more important. The EPT's payment transaction demands more actions, more expressive movements and more time than the CPT, a second stand product. The EPT deliberately limits the speed and effortlessness that come with the digital.

\subsection{The value system of the third stand}

Now, what is the meaning of imposing these limitations on the digital? Why would one want to limit the digital? Our suggestion is: because it grants access to a specific value system, containing values like attentiveness, consciousness and preciousness [1].

Through the process of re-materialization, i.e. by making digital events more physical, these events become larger, more persistent and more characteristic and unique. They urge us to be more attentive and conscious when we engage with them. Our actions that guide these events, and are evoked by them, become more elaborate and nuanced, more important and precious. We believe this should be the very essence of the third stand. By inducing these specific interaction characteristics, third stand products generate a more profound user experience. This profundity is 
what we understand under the "richness" of the physical world. It might shed a new light on the "rich" in rich interaction.

Why would we want something like this? What is the benefit of this profundity? There is more than one answer to this question, since every product has its own context. In the case of the EPT, this profundity surfaced in the form of, what we called, being-in-control and tangibility. Generally speaking, we could say that the physical world's limitations, its persistence, its slowness and its fragility make our actions in it more precious, nuanced and conscious. If we build upon these limitations in our design of digital products and systems, our interaction with them will inherit some of this preciousness, nuance and consciousness. In this respect, limiting the digital is not an aim in itself, but a means to lend certain action routines the importance and weight that they deserve, and that is taken from them by the process of dematerialization. We leave it to the intuition and personality of each designer to decide which action routines are eligible for this approach.

We want to position the third stand as a call to design interactive products that aim for well-thought, significant and attentive actions. Third stand products would exploit interaction in depth, instead of in width, i.e. they handle a few specific tasks very well, instead of, like second stand products, superficially handling many of them. If a designer chooses to adopt the third stand, he might find help and inspiration in the limitations of the physical world.

In Radical Atoms [34], Ishii et al. propose a fictional physical material that has all the malleability of the digital, as well as the physical richness (i.e. the affordances) of the real world. They hypothetically strip the physical of its limitations, since these limitations obviously hinder a complete embodiment of the digital. From a third stand point of view, we would argue that these limitations can be embraced, instead of opposed.

\section{Conclusion}

We proposed a design approach that should guide today's process of dematerialization, and named it the third stand. The third stand builds on rich interaction, and focuses on the border between the physical and the digital world. We wanted to develop this approach, and formulated a research question:

\section{- What is the added value of the third stand?}

In order to answer this question, we designed a payment terminal, and in an experiment, we compared it with a commercial payment terminal. Our experiment showed that our own payment terminal was valued by the participants, but not for its alleged intuitiveness or naturalness. The most efficient terminal turned out to be the commercial one. Our payment terminal was valued for other qualities:

- It offers a stimulating appearance and interaction

- It lends a sense of "being-in-control" to the customer

- It lends a sense of "tangibility" to the customer

These qualities are rather hedonic than pragmatic, and belong to the domain of user experience, rather than to usability. As such, our experiment does not support the familiarity argument that is generally used in the context of embodied interaction. We suggest that embodiment is worth 
striving for, but not only for pragmatic reasons like intuitiveness and naturalness. The reason to rematerialize, as far as our experiment is concerned, lies in hedonic values. Here resides the added value of the third stand: the third stand pleas for embodiment, or re-materialization, from a hedonic perspective, rather than a pragmatic one.

Finally, we aimed at a better understanding of these hedonic values, by suggesting that the third stand builds on the limitations of the physical, and seeks to constrain and channel the digital world, in order to generate an interaction that is more emphasized, important and valuable.

We believe this research is not finished. The third stand and its value system have just been proposed, and should be explored further. The only way to learn about the third stand and to further articulate it, is by bringing it in design practice. We invite design researchers, designers and design students to use it in their research and projects, and to reflect on their work. We hope this leads to further discourse and a deeper comprehension of the argumentation for embodiment.

\section{References}

1. Belk RW (2013) Extended self in a digital world. JCR 40(3): 477-500 https://doi.org/doi 10.1086/671052

2. Blackler A (2008) Intuitive interaction with complex artefacts: empirically-based research. VDM Verlag, Saarbrücken

3. Blackler A, Popovic V, Mahar D (2010) Investigating users' intuitive interaction with complex artefacts. Appl Ergon 41(1): 72-92 https://doi.org/10.1016/j.apergo.2009.04.010

4. Buur J, Jensen MV, Djajadiningrat T (2004) Hands-only scenarios and video action walls: novel methods for tangible user interaction design. In: Proceedings of the 5th conference on Designing interactive systems: processes, practices, methods, and techniques. ACM Press, New York, pp 185-192 https://doi.org/10.1145/1013115.1013141

5. Diefenbach S, Hassenzahl M, Eckoldt K, Hartung L, Lenz E, Laschke M (2017) Designing for well-being : A case study of keeping small secrets. J Posit Psychol 12(2): 151-158 https://doi.org/10.1080/17439760.2016.1163405

6. Diefenbach S, Hassenzahl M, Eckoldt K, Laschke M (2010) The impact of concept (re)presentation on users' evaluation and perception. In: Proceedings of the 6th Nordic Conference on Human-Computer Interaction Extending Boundaries - NordiCHI '10. ACM Press, New York, pp 631-634 https://doi.org/10.1145/1868914.1868991 
7. Diefenbach S, Kolb N, Hassenzahl M (2014) The 'hedonic' in human-computer interaction History, contributions, and future research directions. In: Proceedings of the 10th Conference on Designing Interactive Systems. ACM Press, New York, pp 305-314 https://doi.org/10.1145/2598510.2598549

8. Djajadiningrat JP, Wensveen SAG, Frens JW, Overbeeke CJ (2004) Tangible products: Redressing the balance between appearance and action. Pers Ubiquitous Comput 8(5): 294309

https://doi.org/10.1007/s00779-004-0293-8

9. Dourish P (2001) A history of interaction. In: Dourish P (ed) Where the action is - The foundations of embodied interaction. MIT Press, Cambridge, pp 1-23

https://doi.org/10.1162/leon.2003.36.5.412

10. Dourish P (2001) "Being-in-the-world": embodied interaction. In: Dourish P (ed) Where the action is - The foundations of embodied interaction. MIT Press, Cambridge, pp 99-126 https://doi.org/10.1162/leon.2003.36.5.412

11. Dourish P (2001) Conclusions and directions. In: Dourish P (ed) Where the action is - The foundations of embodied interaction. MIT Press, Cambridge, pp 189-209 https://doi.org/10.1162/leon.2003.36.5.412

12. Dourish P (2001) Foundations. In: Dourish $P(\mathrm{ed})$ Where the action is - The foundations of embodied interaction. MIT Press, Cambridge, pp 127-154 https://doi.org/10.1162/leon.2003.36.5.412

13. Dourish $P$ (2001) Getting in touch. In: Dourish $P(\mathrm{ed})$ Where the action is - The foundations of embodied interaction. MIT Press, Cambridge, pp 25-53 https://doi.org/10.1162/leon.2003.36.5.412

14. Ebert JD (2011) The new media invasion: digital technologies and the world they unmake. McFarland Books, Jefferson

15. Edwards AL (1957) The social desirability variable in personality assessment and research. Dryden, New York

16. Engelen U, De Peuter S, Victoir A, Van Diest I, Van den Bergh O (2006) Verdere validering van de Positive and Negative Affect Schedule (PANAS) en vergelijking van twee Nederlandstalige versies. Gedrag \& Gezondheid 34(2): 89-102 
17. Fishkin KP (2004) A taxonomy for and analysis of tangible interfaces. Pers Ubiquitous Comput 8(5): 347-358

https://doi.org/10.1007/s00779-004-0297-4

18. Frens, JW (2006) Designing for rich interaction - Integrating form, interaction and function. Dissertation, Eindhoven University of Technology

19. Frens JW, Van Campenhout LDE (2014) Advanced cardboard modeling: exploring the aesthetics of the third way. In: Proceedings of the 8th International Conference on Tangible, Embedded and Embodied Interaction. ACM Press, New York, pp 349-352 http://dx.doi.org/10.1145/2540930.2567903

20. Gaver W (2012) What should we expect from research through design? In: Proceedings of the SIGCHI Conference on Human Factors in Computing Systems. ACM Press, New York, pp 937-946

https://doi.org/10.1145/2207676.2208538

21. Gibson JJ (1979) The ecological approach to visual perception. Lawrence Erlbaum Associates, London

22. Hassenzahl M (2003) The thing and I: Understanding the relationship between user and product. In: Blythe M, Overbeeke M, Monk A, Wright P (Eds) Funology, Kluwer Academic Publishers, Dordrecht, pp 31-42 https://doi.org/10.1007/1-4020-2967-5_4

23. Hassenzahl M (2004) The interplay of beauty, goodness, and usability in interactive products. Hum-Comput Interact 19(4): 319-349

https://doi.org/10.1207/s15327051hci1904_2

24. Hassenzahl M (2010) Experience Design: Technology for all the right reasons. Morgan \& Claypool, San Rafael

25. Hassenzahl M, Burmester M, Koller F (2003) AttrakDiff: Ein Fragebogen zur Messung wahrgenommener hedonischer und pragmatischer Qualität. In: Ziegler J, Zwillus G (Eds) Mensch \& Computer 2003. Interaktion in Bewegung, BG Teubner, Stuttgart, pp 187-196 https://doi.org/10.1007/978-3-322-80058-9_19

26. Hassenzahl M, Diefenbach S, Göritz, A (2010) Needs, affect, and interactive productsFacets of user experience. Interact Comput 22(5): 353-362 
27. Hassenzahl M, Eckoldt K, Diefenbach S, Laschke M, Lenz E, Kim J (2013) Designing moments of meaning and pleasure. Experience design and happiness. Int J Des 7(3): 21-31

28. Holmquist LE, Redström J, Ljungstrand P (1999) Token-Based Access to Digital Information. In: Proceeding of the 1st international symposium on Handheld and Ubiquitous Computing. Springer-Verlag, Berlin, pp 234-245

https://doi.org/10.1007/3-540-48157-5_22

29. Hornecker E (2012) Beyond affordance: tangibles' hybrid nature. In: Proceedings of the Sixth International Conference on Tangible, Embedded and Embodied Interaction. ACM Press, New York, pp 175-182

http://dx.doi.org/10.1145/2148131.2148168

30. Hornecker E, Buur J (2006) Getting a grip on tangible interaction: A framework on physical space and social interaction. In: Proceedings of the CHI Conference on Design for Tangible Interactions. ACM Press, New York, pp 437-446

https://doi.org/10.1145/1124772.1124838

31. Hornecker E, Dünser A (2008) Of pages and paddles: Children's expectations and mistaken interactions with physical-digital tools. Interact Comput 21(1): 95-107

https://doi.org/10.1016/j.intcom.2008.10.007

32. Hsieh HF, Shannon SE (2005) Three Approaches to Qualitative Content Analysis. Qual Health Res 15(9): 1277-1288

https://doi.org/10.1177/1049732305276687

33. Hurtienne J, Israel JH (2013) PIBA-DIBA or how to blend the digital with the physical. In: Extended Abstracts of the SIGCHI Conference on Human Factors in Computing Systems. ACM Press, New York

34. Ishii H, Lakatos D, Bonanni L, Labrune JB (2012) Radical atoms: Beyond tangible bits, toward transformable materials. Interactions 19(1): 38-51

https://doi.org/10.1145/2065327.2065337

35. Ishii H, Ullmer B (1997) Tangible bits: towards seamless interfaces between people, bits and atoms. In: Proceedings of the SIGCHI conference on human factors in computing systems. ACM Press, New York, pp 234-241 https://doi.org/10.1145/604046.604048 
36. Jacob RJK, Girouard A, Hirshfield LM, Horn M, Shaer O, Solovey ET, Zigelbaum J (2008) Reality-based interaction: a framework for post-WIMP interfaces. In: Proceedings of the SIGCHI conference on human factors in computing systems. ACM Press, New York, pp 201-210

\section{https://doi.org/10.1145/1357054.1357089}

37. Jetter HC, Geyer F, Schwarz T, Reiterer H (2012) Blended interaction - Toward a framework for the design of interactive spaces. Workshop Designing Collaborative Interactive Spaces (DCIS 2012) at AVI 2012

38. Klemmer S, Hartman H, Takayama L (2006) How bodies matter: five themes for interaction design. In: Proceedings of the 6th conference on designing interactive systems. ACM Press, New York, pp 140-149

https://doi.org/10.1145/1142405.1142429

39. Koskinen I, Zimmerman J, Binder T, Redström J, Wensveen S (2011) Design research through practice: From the lab, field, and showroom. Elsevier, Philadelphia

40. Magaudda P (2011) When materiality 'bites back': Digital music consumption practices in the age of dematerialization. J Consum Cult 11(1): 15-36 https://doi.org/10.1177/1469540510390499

41. Negroponte N (1995) Being digital. Alfred A. Knopf, New York

42. Odom W, Zimmerman J, Forlizzi J (2011) Teenagers and their virtual possessions: Design opportunities and issues. In: Proceedings of the SIGCHI Conference on Human Factors in Computing Systems. ACM Press, New York, pp 1491-1500 https://doi.org/10.1145/1978942.1979161

43. Overbeeke CJ, Djajadiningrat JP, Wensveen SAG, Frens JW (2001) Set me free, give me degrees of freedom. In: Proceedings of the Scuola Superiore G. Reiss Romoli Conference

44. Partala T, Kallinen A (2012) Understanding the most satisfying and unsatisfying user experiences: Emotions, psychological needs, and context. Interact Comput 24(1): 25-34 https://doi.org/10.1016/j.intcom.2011.10.001

45. Raghubir P, Srivastava J (2008) Monopoly money: The effect of payment coupling and form on spending behavior. J Exp Psychol - Appl 14(3): 213-225 
46. Sheldon KM, Elliot AJ, Kim Y, Kasser T (2001) What is satisfying about satisfying events? Testing 10 candidate psychological needs. J Pers Soc Psychol 80(2): 325-339 https://doi.org/10.1037//0022-3514.80.2.325

47. Siddiqui S, Turley D (2006) Extending the self in a virtual world. Adv Consum Res 33: 647648

48. Soffer O, Eshet-Alkalai Y (2009) Back to the future: An historical perspective on the pendulum-like changes in literacy. Mind Mach 19 (1): 47-59

https://doi.org/10.1007/s11023-008-9119-1

49. Ullmer B, Ishii H, Glas D (1998) MediaBlocks: Physical containers, transports, and controls for online media. In: Proceedings of the 25th annual Conference on Computer Graphics and Interactive Techniques. ACM Press, New York, pp 379-386 https://doi.org/10.1145/280814.280940

50. Ullmer B, Ishii H, Jacob RJK (2005) Token+constraint systems for tangible interaction with digital information. TOCHI 12(1): 81-118 https://doi.org/10.1145/1057237.1057242

51. Van Campenhout LDE (2016) Materializing the third stand. In: Van Campenhout LDE (ed) Physical interaction in a dematerialized world. Dissertation, Eindhoven University of Technology, pp 97-124

52. Van Campenhout LDE (2016) Experiment. In: Van Campenhout LDE (ed) Physical interaction in a dematerialized world. Dissertation, Eindhoven University of Technology, pp $141-166$

53. Van Campenhout LDE, Frens JW, Hummels CCM, Standaert A, Peremans H (2012) Hard cash in a dematerialized world. In: Proceedings of the 14th International Conference on Engineering \& Product Design Education. The Design Society, Westbury, pp 121-126

54. Van Campenhout LDE, Frens JW, Overbeeke CJ, Standaert A, Peremans H (2013) Physical interaction in a dematerialized world. Int J Des 7(1): 1-18

55. Van Campenhout LDE, Frens JW, Hummels CCM, Standaert A, Peremans H (2016)

Touching the dematerialized. Pers Ubiquitous Comput 20(1): 147-164 http://dx.doi.org/10.1007/s00779-016-0907-y 
56. van Dijk J, Moussette C, Kuenen S, Hummels C (2013) Radical clashes: what tangible interaction is made of. In: Proceedings of the 7thinternational conference on tangible, embedded and embodied interaction. ACM Press, New York, pp 323-326 https://doi.org/10.1145/2460625.2460680

57. Van Wijk C (2000) Toetsende statistiek: Basistechnieken. Een praktijkgerichte inleiding voor onderzoeker van taal, gedrag en communicatie. Coutinho, Bussum

58. Weiser M, Brown JS (1996) Designing calm technology. PowerGrid Journal 1(1): 75-85

59. Zimmerman J, Forlizzi J (2008) The role of design artifacts in design theory construction. Artifact 2(1): 41-45 http://dx.doi.org/10.1080/17493460802276893

60. Zimmerman J, Forlizzi J, Evenson S (2007) Research through design as a method for interaction design research in HCI. In: Proceedings of the SIGCHI Conference on Human Factors in Computer Systems. ACM Press, New York, pp 493-502 http://dx.doi.org/10.1145/1240624.1240704

61. Zimmerman J, Stolterman E, Forlizzi J (2010) An analysis and critique of Research through Design: towards a formalization of a research approach. In: Proceedings of the 8th Conference on Designing Interactive Systems. ACM Press, New York, pp 310-319 https://doi.org/10.1145/1858171.1858228 